\title{
Innovation of Network Information Security Research on Network Marketing Strategy of Small and Medium Sized Enterprises in Big Data Era
}

\author{
Feng Jujun \\ Shaanxi University of Chinese Medical, Shaanxi, China,712046
}

Keywords: Big data era, small and medium enterprises, network marketing.

\begin{abstract}
With the development and maturity of internet technology and computer technology, economic activities begin to develop towards network. Enterprises gradually realize the importance of internet market in the process of development and construction. With the help of big data development and construction, they begin to carry out network marketing with each other. However, with the development of enterprise network marketing activities, enterprises have gradually come to realize the difficulty of network marketing, personnel and capital issues are more prominent, especially small and medium-sized enterprises. There is a big gap between small and medium-sized enterprises and large enterprises, and the implementation of network marketing strategy is more difficult. Because of the lack of scientific management concepts, most of the small and medium-sized enterprises 'network marketing ended in failure. Therefore, under the background of big data era, this paper makes an analysis and research on the network marketing strategy of small and medium-sized enterprises, understands the importance of network marketing in the development and construction of small and medium-sized enterprises, combines with the problems existing in the network marketing of small and medium-sized enterprises, and puts forward pertinent suggestions for the network marketing of small and medium-sized enterprises, hoping to help small and medium-sized enterprises in Further development and construction in the era of data.
\end{abstract}

\section{Introduction}

Twenty-first Century is a time of big data explosion, or twenty-first Century is the era of big data. In the era of big data, it provides people with better opportunities for development. People's speed in data collection has increased significantly. It can find a specific direction for future development and construction, and effectively reduce errors in the process of development. Any enterprise has the same development opportunities in the era of big data, but because of their limited comprehensive strength, SMEs cannot clearly recognize their own positioning in the process of development and construction, and the reform process is slow. All these problems make it difficult for SMEs to develop in the era of big data. Therefore, it is of great significance for the development and construction of SMEs to study the network strategy of SMEs in the era of big data ${ }^{[1]}$. In this paper, take company A as an example, analysis its internet marketing strategy. The below Figure 1 
shows the internet marketing organization chart of company A.

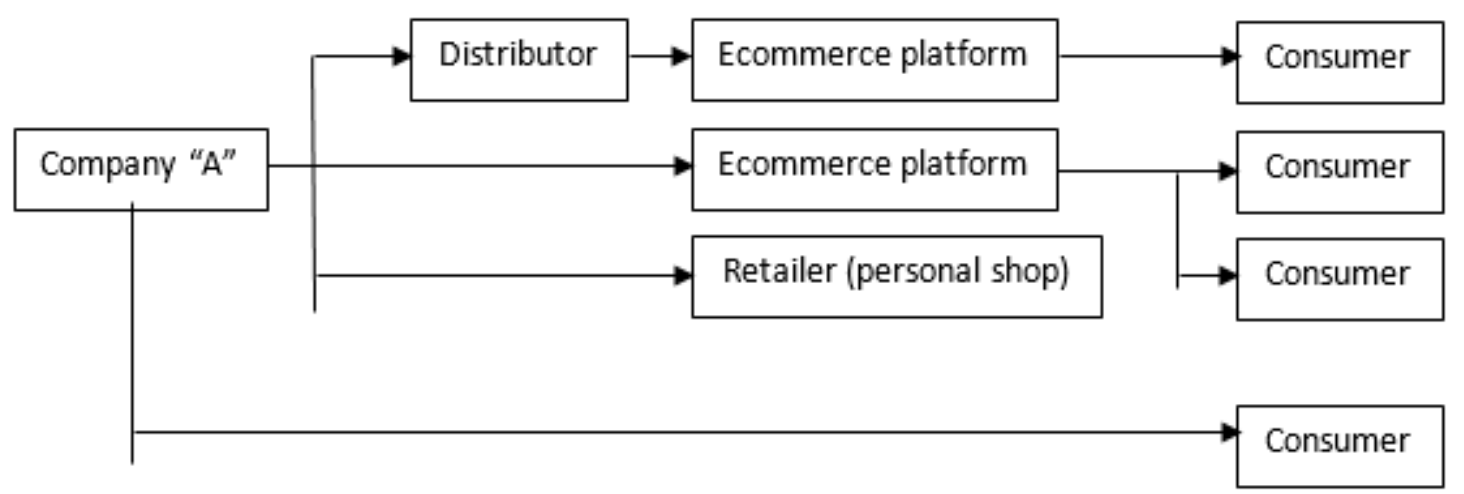

Figure 1 Enterprise A network marketing structure chart

2. The role of small and medium sized enterprises in network marketing under the background of big data Era

\subsection{Get more data information}

In the era of big data, the speed of information generation and update is faster, and the efficiency of information dissemination and integration is significantly improved. In this general environment, SMEs can obtain more data information in the shortest time and predict their future development trend in advance with the help of data information collected by themselves. If SMEs have more network marketing data, they will have a better understanding of the future development and construction of the market. A very accurate market analysis can help SMEs adjust and improve their own development and construction trends, ensure that Mismarking strategies are formulated scientifically and reasonably, and improve the marketing quality of SMEs. Further development and construction of small businesses ${ }^{[2]}$.

\subsection{Enhance network marketing targeting}

Under the background of e-commerce, the network impact of some small and medium-sized enterprises in China is almost everywhere. By using network resources reasonably, large-scale marketing publicity can be realized, which greatly increases the actual cost of the network impact of small and medium-sized enterprises themselves. Moreover, the marketing results are not good enough. However, in the context of the era of big data, some small and medium-sized enterprises, through reasonable access to and analysis of many market dynamic data information. Then, in the actual development process, it will continue to improve the needs of some designated customer groups, and the products it needs can be re-analysed and designed to ensure that the price is the most reasonable and scientific. In addition, to a large extent, this can also avoid the phenomenon of taking on larger cost expenditure in the actual marketing process of the whole network. The implementation of Internet marketing has effectively broken the constraints of time and space. In the process of network marketing, small and medium-sized enterprises can effectively use the convenient conditions provided by the era of big data, through the minimum economic costs and resources, in exchange for more extensive publicity space, enhance publicity efforts, and effectively sell their own development ideas and products. In the process of development and construction, small and medium-sized enterprises need to formulate marketing strategies according to the characteristics of their own customer groups, to show the pertinence of marketing strategies, to 
strictly prohibit the emergence of a wide network, marketing investment problems, and to intensify the operational burden of small and medium-sized enterprises. In the process of developing network marketing of small and medium-sized enterprises, with the help of big data era, it can effectively enhance the pertinence of network marketing, reduce the economic cost of network marketing, and enhance the economic benefits of network marketing.

\section{Problems in network marketing of small and medium sized enterprises under the background of big data Era}

\subsection{The understanding of the big data era is not enough}

The era of big data is developing rapidly, and visionary enterprises in different fields have already recognized it to the importance of self-development and construction in the era of big data, and then to use the era of big data to analyse and study their own marketing, grasp the opportunities brought by the era of big data, change their own development model, and promote their own development and construction. However, in the process of development and construction, some small and medium-sized enterprises have not realized the importance and influence of the big data era. They mistakenly believe that there is no connection between their own development and construction and the big data era. They still adopt the original marketing mode, even if they adopt network marketing, but the proportion of investment in network marketing is low. In this case, SMEs need to be affected by the traditional market and network environment, which seriously limits the further development and construction of SMEs. At present, many small and medium-sized enterprises in our country have obviously insufficient understanding of the impact of big data. They think that under the background of big data era, they do not have too much influence on their own network marketing. They still rely on the use of some more traditional marketing modes and methods, which will lead to actual marketing. In the process, there are many development opportunities that are difficult to make full use of big data. Therefore, some small and medium enterprises in China have little profit in their own network marketing ${ }^{[3]}$.

\subsection{Lack of network infrastructure}

Network infrastructure is the actual development basis of the network influence of some small and medium-sized enterprises in China, which is in the background of big data. A perfect infrastructure can largely promote the smooth development and implementation of the follow-up network marketing of relevant small and medium-sized enterprises. It can not only reduce the marketing cost of small and medium-sized enterprises to a great extent, but also effectively enhance their marketing revenue. In order to carry out network marketing, we need to have a very perfect network infrastructure, which includes not only Internet equipment and computers, but also the ability to reform and improve. Perfect network infrastructure is the basic condition for the smooth implementation of network marketing. It can effectively reduce the problems in the implementation of network marketing and improve the economic benefits of enterprises. But at this stage, small and medium-sized enterprises are affected by capital and technology level, and the network infrastructure is not yet perfect, resulting in the implementation of network marketing of small and medium-sized enterprises cannot be carried out smoothly, increase the investment of small and medium-sized enterprises in network marketing, and increase the operation cost of small and medium-sized enterprises. And the implementation of Internet marketing has also been significantly affected $^{[4]}$. 
4. Improving network marketing measures for small and medium sized enterprises in the era of big data

\section{1 reasonable market positioning}

As a new marketing method, network marketing has been highly concerned and relied on by small and medium-sized enterprises because of its good marketing effect, which has become the hope of further development and construction of small and medium-sized enterprises. Although the effect of network marketing is remarkable, not any product can be publicized by means of network marketing. Before the network marketing, small and medium-sized enterprises need to make a comprehensive and meticulous evaluation of the network market, have a holistic understanding of the principles and objectives of the network marketing, define the market orientation according to the industry development trend, and then ensure that their products are in line with the network marketing, and then carry out the network marketing work. Network marketing is implemented in the era of big data. Big data can provide a variety of marketing means for network marketing. Customers have the leading power in the era of big data. Customers put forward more stringent requirements for enterprise network marketing. Small and medium-sized enterprises must have accurate and reasonable market positioning in the development of network marketing activities, and effectively improve the quality and effect of network marketing of small and medium-sized enterprises under the condition of guaranteeing the level of network marketing ${ }^{[5]}$.

\subsection{Establish specialized websites}

Take diversified construction situation to provide consumers with pictures, text, video and other forms of services; Third, in the actual application process of the website, enterprises should actively communicate with visitors, timely understand the views of visitors, combined with the actual needs of visitors, to update and improve the website. Small and medium-sized enterprises should increase their investment in human, material and financial resources in the construction of network platform in the process of carrying out network marketing. It can achieve some cooperation with some large enterprises and jointly build the infrastructure of network marketing. At the same time, our government departments should also vigorously help some small and medium-sized enterprises in the construction of network infrastructure in Jining and increase some necessary investment appropriately. The purpose of this is to ensure that the network infrastructure can truly achieve efficient and stable operation. This is also an important precondition to ensure that all small and medium-sized enterprises implement online marketing means in the context of big data era.

\section{Concluding}

In summary, according to the problems existing in the network marketing of small and medium-sized enterprises under the background of big data era, in the future, the network marketing activities of small and medium-sized enterprises should be carried out from the aspects of attention, network technology facilities, brand publicity, management mechanism and personnel training, so as to effectively enhance the network marketing. Grasping the opportunities provided by the era of big data for the development and construction of small and medium-sized enterprises, standardizing the awareness of network marketing behaviour, enhancing the pertinence of network marketing, meeting the needs of different consumers for enterprises 'products, helping small and medium-sized enterprises collect timely feedback from consumers, and enhancing the competitiveness of small and medium-sized enterprises in the market is become the main job of government. 


\section{References}

[1] Li Xiaomei. Dilemma and Improvement Strategy of Small and Medium-sized Enterprises Using Big Data Marketing [J]. China Statistics, 2017 (12): 16-18.

[2] Yu Rongrui. Research on Internet Marketing Strategy of SMEs in the Background of Big Data Era [J]. Human Resource Management, 2017 (07): 14-16.

[3] Lv Wei. The development of e-commerce in small and medium enterprises in the era of big data, [J]. intelligence, 2016 (17): 244+246.

[4] Li Chunlin. The choice of marketing innovation mode for SMEs in big data era [J]. Economic and trade practice, 2016 (02): $212+214$.

[5] Kong Ying. Analyzing the Internet Marketing Strategy of Small and Medium-sized Enterprises in the Background of Big Data Era [J]. Modern Economic Information, 2015 (23): 287-288. 